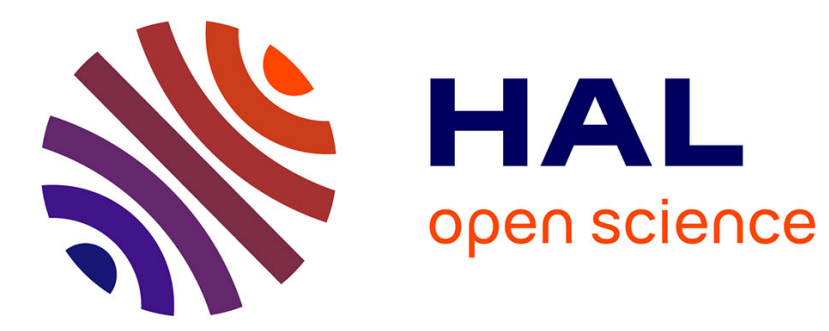

\title{
Constant long photoperiod inhibits the onset of the reproductive cycle in roach females and males
}

Imen Ben Ammar, Sylvain Milla, Yannick Ledore, Fabrice Teletchea, Pascal

Fontaine

\section{- To cite this version:}

Imen Ben Ammar, Sylvain Milla, Yannick Ledore, Fabrice Teletchea, Pascal Fontaine. Constant long photoperiod inhibits the onset of the reproductive cycle in roach females and males. Fish Physiology and Biochemistry, 2020, 46 (1), pp.89-102. 10.1007/s10695-019-00698-3 . hal-02930917

\section{HAL Id: hal-02930917 \\ https://hal.science/hal-02930917}

Submitted on 4 Sep 2020

HAL is a multi-disciplinary open access archive for the deposit and dissemination of scientific research documents, whether they are published or not. The documents may come from teaching and research institutions in France or abroad, or from public or private research centers.
L'archive ouverte pluridisciplinaire HAL, est destinée au dépôt et à la diffusion de documents scientifiques de niveau recherche, publiés ou non, émanant des établissements d'enseignement et de recherche français ou étrangers, des laboratoires publics ou privés. 
1 Constant long photoperiod inhibits the onset of the reproductive cycle in roach females

2 and males

3 Imen Ben Ammar ${ }^{(a, 1)}$, Sylvain Milla ${ }^{(a)}$, Yannick Ledoré ${ }^{(a)}$, Fabrice Teletchea ${ }^{(a)}$, Pascal

$4 \quad$ Fontaine ${ }^{(a)}$

5

6

(a) : Université de Lorraine, INRA, UR AFPA, F-54000, Nancy

7 Corresponding authors: p.fontaine@univ-lorraine.fr

8

imen.benammar@yahoo.fr

9

Equipe Domestication en Aquaculture Continentale, UR AFPA - INRA, Université de

11 Lorraine. Faculté des Sciences, Entrée 1B, 5ème étage, Boulevard des Aiguillettes, BP 236

12

F - 54506 Vandœuvre-lès-Nancy

13

Tél: (+33) 372745699

\footnotetext{
${ }^{1}$ Current address: Unité de Recherche en Biologie environnementale et évolutive, URBE, Université de Namur.
} 61, rue de Bruxelles, 5000, Namur, Belgique 


\section{Abstract}

Photoperiod and temperature are commonly accepted as the determinant factors for the control of the reproductive cycle in freshwater fishes. However, this determining effect is dependent on fish species. While applying a constant long photoperiod has an inhibitory effect in some species, the same photoperiodic manipulation has a stimulating effect in others. In cyprinids, a decrease in temperature or photoperiod can induce the gonad recrudescence. However, in roach Rutilus rutilus an early spring spawner cyprinid, there is little knowledge about the cueing role of each environmental factor. The aim of this work was to study the effect of a constant long photoperiod on the gametogenesis in roach. Fish were kept under either naturally simulated photoperiod or artificial constant long photoperiod and sampled at three times: at the beginning of photoperiod decrease, at the beginning of temperature decrease, and at the end of temperature decrease. Morphological parameters (gonado-somatic, hepato-somatic and viscera-somatic indexes), plasma sexual steroids, and proportion of gametogenesis stages were estimated at each sampling time. The results showed that a constant, long photoperiod exerted inhibitory effects on gametogenesis advancement in both females and males that could stem from decrease of sex steroid production. Roach displayed a similar response to photoperiodic manipulations to other early spring spawners like percids, such as European perch, yellow perch and pikeperch. These results clearly showed the cueing role of the photoperiod in the induction of the reproductive cycle in roach.

Key words: Photoperiod manipulation, Inhibition, onset of reproductive cycle, Roach. 


\section{Introduction}

Life history of temperate fish species is regulated by seasonal changes in climate, daylength, and food supplies. These species show a marked seasonality particularly with regards to reproductive cycle and spawning (Baggerman, 1980). In temperate fish, the synchronicity of the reproductive cycle is important because it ensures that offspring are produced when environmental conditions and food supply are the most suitable for their survival and development (Sumpter, 1990; Teletchea and Fontaine, 2014). Both environmental cues and intrinsic factors are involved in the control of the reproductive cycle. Rosa and Bryant (2003) divided them into determining factors, responsible for the synchronicity of reproductive cycle, and modulating factors that can influence the progress and the quality of reproduction. From all these factors, photoperiod and temperature are commonly accepted as the two environmental cues that provide a timing message (Bromage et al., 2001; Wang et al., 2010). Studies showed that photoperiod provides an accurate, reliable, and reproducible signal that determines the onset of the reproductive cycle in many temperate species (Migaud et al., 2010). Photoperiodic manipulations alone can inhibit, advance, or delay the induction of the reproductive cycle, depending on the species and the time of application (Migaud et al., 2010). Applying a constant long photoperiod can inhibit the onset of the reproductive cycle in many species, such as the European seabass, Dicentrarchus labrax, (Bayarri et al., 2004), European perch, Perca fluviatilis, (Migaud et al., 2004a), yellow perch, Perca flavescens, (Shewmon et al., 2007), and turbot, Scophthalmus maximus, (Imsland et al., 1997). However, in other species like three-spined stickleback, Gasterosteus aculeatus, and catla, Gibelion catla, constant long photoperiod seems to have a stimulating effect on the gametogenesis (Borg and Ekström, 1981; Bornestaf et al., 1997; Dey et al., 2005). It can advance the ovarian development like in stone moroko, Pseudorasbora parva, (Zhu et al., 2014), and even allow obtaining two annual spawns in chub, Squalius cephalus, (Poncin et al., 1987). 
Cyprinids have colonized a wide variety of freshwater biotopes and are the most widely farmed fish in the world. It is accepted that constant conditions of both temperature and photoperiod do not generally allow the induction of their reproductive cycle (Kestemont, 1990; Scott, 1979). However, studies have shown or suggested that a decrease in temperature or photoperiod is required to induce the gonad recrudescence in some species, such as gudgeon, Gobio gobio, (Kestemont, 1990) and common carp, Cyprinus carpio, (Davies et al., 1986; Davies and Hanyu, 1986).

The roach, Rutilus rutilus, is a cyprinid fish that is ubiquitous in European freshwater ecosystems. This species has numerous interests for recreational fishing, pond polyculture (restocking market), and ecotoxicology as sentinel species for endocrine disruption (Tyler and Jobling, 2008). Based on observations in natural conditions, several authors suggest the cueing role of temperature, however, there is no knowledge regarding the role of photoperiod or temperature on the onset of the reproductive cycle in this species. For example, Tarkan (2006) suggests that temperature drives the reproductive cycle in this species. Escaffre and Billard (1976) also strongly suggest the action of temperature, but with a potential implication of photoperiod in the entrainment of reproductive cycle. Moreover, according to Gillet and Quétin (2006), roach belongs to a group of cyprinids that initiate gonad development during the autumn, under the effect of decreasing temperature and photoperiod together. The application of a long constant photoperiod during the onset of the reproductive cycle is known as inhibitory in some fish species, belonging to temperate early spring spawners and stimulatory in other cyprinids. As roach is an early spring spawning cyprinid (Teletchea et al., 2009), the aim of this work is to study the effect of such a photoperiod on the induction of the reproductive cycle in order to improve knowledge about its potential cueing role in this species. 


\section{Materials and methods}

This work is based on a morpho-anatomic (gonado-somatic index GSI, visceral-somatic index VSI and hepato-somatic index HSI, oocyte diameter OD), histological (developmental stage of gametogenesis) and physiological (estradiol E2, testosterone T, 11-ketotestosterone 11-KT and Alkali-labile phosphate levels ALP) analysis of the broodstock sampled at three times during and after the induction of their reproductive cycle which can be driven by photoperiod, temperature or both of them. In females, the proliferation and the growth of the oocytes (GSI, OD and the developmental stages) are known to be driven by the estradiol (produced by the conversion of testosterone) and can be anterior or concomitant with the endocytosis of the lipids and vitellus vesicles (Miura et al., 2007). The 11-Ketotestorone (produced by the conversion of testosterone) can also be involved in those stages (Rohr et al., 2001). The vitellogenesis occurs right after with the incorporation of the vitellogenin (ALP levels) produced by the liver (HSI) under the estrogenic control. In males, E2 at very low levels and 11-KT are implied in the renewal and the proliferation of the spermatogonia respectively (Knapp and Carlisle, 2011) which affect the GSI and the developmental stages in testis. Broodstock can use a part of their visceral reserves during these phases (VSI).

\subsection{Fish}

Roach (origin: pond, GAEC piscicole du Saulnois, Gelucourt, Moselle, France, reared under natural conditions, mean weight $61 \pm 8 \mathrm{~g}$ ) were received on March, $14^{\text {th }} 2012$ (water temperature at arrival $8^{\circ} \mathrm{C}$ ). Fish were kept in an outdoor water-recirculating system, located at the Domaine de la Bouzule, Laneuvelotte, Meurthe et Moselle, France (Migaud et al., 2004b). They were placed into two $3 \mathrm{~m}^{3}$ polyester tanks, partially covered for acclimation to Recirculating aquaculture systems (RAS) conditions. During acclimation, roach were fed a commercial feed (Le Gouessant Ombrine $N^{\circ} 4$ ). On June $21^{\text {st }} 2012,270$ fish were transferred to our laboratory facilities (University of Lorraine, France) in indoor water-recirculating 
systems, under controlled environmental conditions. They were placed in six polyester tanks (500L) at a density of 45 fish per tank. At the beginning of the experiment (Day1), fish showed low gonado-somatic index GSI $(1.4 \pm 0.3 \%$ in females and $0.7 \pm 0.5 \%$ in males $)$ and were in sexual rest period. Tanks were totally covered and light was provided by fluorescent bulbs (Osram daylight, 150-300 lx at the water surface). Three tanks were maintained under constant photoperiod 16L:8D $(\mathrm{CP})$ which is known to be inhibitory and represents the longest daylength to which those species are exposed under this latitude. Three other tanks were maintained under natural simulated photoperiod (NSP) based on the natural variations observed in Nancy, France (Figure 1). The temperature followed the natural decrease occurring in Nancy $(48.42 \mathrm{~N}, 06.12 \mathrm{E})$, as described in a previous works (Figure 1, Ben Ammar et al., 2017, 2015). Experiment was performed according to the European (directive 2010/63/EU) and French legislation (law No 2010-788 of 12 July 2010 on national commitment to the environment) for fish welfare during animal experimentation.

\subsection{Organ and blood sampling}

Fish were sampled three times: June $28^{\text {th }}$ before the start of the photoperiod decrease in NSP tanks (Day1), September $13^{\text {th }}$ as temperature started decreasing (Day78) and November $21^{\text {st }}$ (Day149) corresponding to the gonadal maturation (GSI increase and appearance of secondary oocytes in females, Geraudie et al. 2010a; Figure 1). At each sampling date, eight fish were randomly caught in each tank to get, if possible, three females and three males (no sexual dimorphism). Fish were anesthetized by immersion into a 2-phenoxyethanol solution for 2-3 $\min (0.4 \mathrm{~mL} / \mathrm{L}$, Sigma). Blood was removed from the caudal vein using a syringe, stored on ice in heparinised microtubes, and finally centrifuged at $2860 \mathrm{~g}$ at $15^{\circ} \mathrm{C}$ for $25 \mathrm{~min}$ (centrifuge Jouan C-412). Aliquots of plasma were stored at $-20{ }^{\circ} \mathrm{C}$ until sexual steroids ELISA assays. After blood sampling, fish were euthanized by overdose of 2-phenoxyethanol solution $(4 \mathrm{~mL} / \mathrm{L})$. Fish were measured $(\mathrm{cm})$, weighed $(\mathrm{g})$, and dissected for gonad, viscera 
and liver weight $(\mathrm{g})$ determination in order to calculate the gonado-somatic $(G S I=$ $\left.\frac{100 \times \text { Gonad weight }}{\text { Bodyweight }}, \%\right)$, the visceral-somatic $\left(V S I=\frac{100 \times \text { Visera weight }}{\text { Bodyweight }}, \%\right)$ and the hepatosomatic indexes $\left(H S I=\frac{100 \times \text { Liver weight }}{\text { Body weight }}, \%\right)$, respectively.

\subsection{Gonadal histology}

Samples of both ovaries and testis were stored in a Bouin-Holland solution for one week, washed once with water, twice with $70 \%$ ethanol and stored in absolute ethanol (Ben Ammar et al., 2015). Then, fragments of gonads were cut into $5 \mathrm{~mm}$ thick slices, dehydrated with OTTIX solution (DIAPATH SpA, Italy/ MM France), and embedded in a paraffin substitute dubbed Diawax (DIAPATH SpA, Italy / MM France) (adapted from Langeron, 1913).

For females, sections of $6 \mu \mathrm{m}$ were cut from the Diawax block and stained with a trichrome: haematoxylin Gill III (VWR), 0.5\% phloxine B (VWR) and 0.5\% light green (Sigma), according to Rinchard and Kestemont (1996). The stage of oocyte development was determined according to Le Menn et al. (2007). Six stages were considered:

- Primary oocyte (S1): oocytes with vacuole free cytoplasm

- Early cortical stage (S2): Appearance of yolk vesicles, occupying 2 or 3 rings in the cytoplasm periphery.

- Late cortical stage (S3): Oocytes are full of yolk vesicles. Follicular and cellular layers are differentiated.

- Early vitellogenesis (S4): Appearance of yolk globules in the centre of oocytes.

- Later vitellogenesis (S5): Oocytes accumulate yolk globules and yolk vesicles at the periphery of the cytoplasm. 
- Atretic oocyte (S6): Degenerated cells without nuclear, the cytoplasm is filled with yolk granules giving a red-orange-coloured oocyte (Geraudie et al., 2010a)

As roach showed synchronous gonad development (Rinchard and Kestemont, 1996), the oocyte diameter was measured on 30 oocytes representing the most frequently observed stage by using an optical microscope (Nikon eclipse Ni) equipped with an ocular camera (Nikon DS-Fi2, 5MP) and the software provided with NIS-Elements®. Percentages of the different developmental stages were calculated by counting the number of oocytes in each development stage, multiplied by 100 and divided on the total number of oocytes.

For males, sections of $4 \mu \mathrm{m}$ were cut from the Diawax block and stained with a trichrome: Regaud iron haematoxylin (solution from crystalline haematoxylin Merck), 1\% PonceauFushine of Masson (Sigma) and 0.1\% light green (Sigma). Testis development was monitored according to the presence of different sperm cell types (Turner, 1919):

- Type A spermatogonia (SpgA): the largest cells of the germ line with a voluminous, irregular nucleus surrounded by voluminous cytoplasm.

- Type B spermatogonia ( $\mathrm{SpgB})$ : similar to type A spermatogonia but smaller.

- Spermatocytes (SPC): smaller than spermatogonia and identified by densely staining chromatin.

- Spermatids (SPD): larger than spermatozoa with a regularly spherical, dense nucleus.

- Spermatozoa (SPZ): recognized by their kidney-shaped cell with a light-coloured hairlike tail.

Percentages of the different developmental stages were calculated by counting the area of cysts from each spermatogenic stage, multiplied by 100, and divided on the total area in three images taken from the periphery, the middle, and the lumen of the testis. 


\subsection{Steroids and vitellogenin assays}

Estradiol $\left(\mathrm{E}_{2}\right)$ was assayed on $50 \mu \mathrm{L}$ of plasma using the DIAsource E2-ELISA kit (DIAsource, KAP0621). When necessary, dilutions from 1/20 to 1/70 of the plasma samples were performed. Sensitivity was $5 \mathrm{pg} / \mathrm{mL}, \mathrm{CV}$ intra-assay varied between $3.1 \%$ and $2.6 \%$ and CV inter-assays varied between $4.7 \%$ and $2.4 \%$ for low and high levels, respectively.

Testosterone ( $\mathrm{T}$ ) was assayed on $25 \mu \mathrm{L}$ of plasma using the DIAsource Testosterone ELISA Kit (DIAsource, KAPD1559). When necessary, a 1/2 dilution of the plasma samples was performed. Sensitivity was $0.083 \mathrm{ng} / \mathrm{mL}, \mathrm{CV}$ intra-assay varied between $1.5 \%$ and $9.5 \%$ and CV inter-assays varied between $7.6 \%$ and $8.7 \%$ for low and high levels, respectively.

The androgen 11-ketotestosterone (11KT) was assayed on $50 \mu \mathrm{L}$ of plasma diluted $1 / 50$ in ELISA buffer using the Cayman 11-keto Testosterone EIA Kit (Cayman, 582751). Sensitivity was $1.3 \mathrm{pg} / \mathrm{mL}, \mathrm{CV}$ intra-assay varied between $2.6 \%$ and $8.4 \%$ and CV inter-assays varied between $9.4 \%$ and $12.1 \%$ for low and high levels, respectively.

Vitellogenein was indirectly estimated with Alkali-labile phosphate levels (ALP, $\mu \mathrm{g} / \mathrm{ml}$ ). ALP levels were assayed on $80 \mu \mathrm{L}$ of plasma. The procedure consists of precipitation of high molecular weight proteins in the presence of trichloroacetic acid (20\%), followed by three pellet washing sessions using pure ethanol; a solution of chloroform, diethyl ether and pure ethanol (1:2:2), and finally diethyl ether. The pellet was dried for 20 minutes, then dissolved in $\mathrm{NaOH}$ solution $(2 \mathrm{~N})$, heated to $100^{\circ} \mathrm{C}$ for 15 minutes, and finally phosphate release was neutralized by adding cold $\mathrm{HCl}$ solution $(2 \mathrm{~N})$. Phosphates were assayed by Stanton method (Stanton, 1968) and ALP levels were calculated from a standard curve of phosphorus that ranged between 0.2 and $6 \mu \mathrm{g} / \mathrm{ml}$ (adapted from Gagné and Blaise, 2000). 


\subsection{Statistical analysis}

204

205

206

207

208

209

210

211

212

213

All statistical analyses were performed using the free software $\mathrm{R}$ version 3.3.1 ( $\mathrm{R}$

Development Core Team, 2005). For each modality, analyses were run in duplicate on eight individual sampled at each time from each tank (three tanks per modality). For all the dependant variables, homogeneity of variances was previously tested using Levene test (leveneTest, package 'car', Fox et al. 2014). For each sex, data were analysed by a linear mixed model (lmer, package 'Ime4', Bates et al. 2014) with the photoperiod type and the sampling time as fixed effects and the tank as random effect: model=lmer $(Y \sim$ photoperiod_type*sampling_time+(1|Tank $))$ with $Y$ : dependant variable. For model validation, residuals were tested for homogeneity and normality using residuals $v s$ fitted values and sample $v s$ theoretical quantiles (Q-Q) plots, respectively (plotresid, package 'RVAideMemoire', Hervé 2015). If necessary, data were log-transformed, arcsin root square transformed (only for data expressed in percentage), or Box-Cox transformed. When the model was validated, an anova table for various statistical models was performed to calculate F-tests (Anova, package 'car', Fox et al. 2014) followed by a Least-squares means (predicted marginal means) comparisons as a post-hoc test (lsmeans, package '1smeans', Lenth, 2016).

When data, even transformed, did not met the assumptions for linear mixed model (homogeneity of variance and normality of residuals), we used the aligned rank transformation for nonparametric factorial analysis (aligned.rank.transform, package 'ART', Villacorta, 2015) from Higgins and Tashtoush (1994) formula, followed by a pairwise comparison using Tukey and Kramer test with Tukey-Dist approximation for independent samples (posthoc.kruskal.nemenyi.test, package 'PMCMR', Pohlert, 2016). The level of significance used in all tests was $\mathrm{p}<0.05$. 


\section{Results}

\subsection{Morpho-anatomic indexes}

In both sexes, hepato-somatic index (HSI) varied with sampling time, showing similar values between day 1 and 78 and increasing significantly between day 78 and day $149(\mathrm{p}<0.001)$ (Table 1). Visceral-somatic index (VSI) varied significantly depending on the interaction between sampling time and photoperiod $(\mathrm{p} \leq 0.001)$. It was significantly higher in females and males reared under constant photoperiod $(\mathrm{CP})$ at day $149(\mathrm{p}<0.05)$.

\subsubsection{Gonad development}

In both sexes, gonado-somatic index (GSI) varied depending on the interaction between photoperiod and sampling time (Figure 2). At day 1, there was no significant difference between fish reared under natural simulated photoperiod (NSP) and those reared under CP. In females, GSI increased significantly between day 1 and day 78 (Figure 2.1) in the group reared under NSP $(p=0.025)$ and between day 78 and day 149 for those reared under CP $(\mathrm{p}=0.022)$. Moreover, GSI was significantly higher in females reared under NSP compared to those reared under CP at both day $78(\mathrm{p}<0.001)$ and day $149(\mathrm{p}<0.001)$. In males (Figure 2.2), GSI increased significantly between day 1 and day 78 in roach reared under NSP only $(\mathrm{p}<0.001)$, but did not show any significant difference over this period relating to photoperiod. GSI increased between day 78 and day 149 in all males ( $<<0.001$ in both cases), and displayed significantly higher values in males reared under NSP compared to those reared under CP $(\mathrm{p}<0.001)$.

Females displayed oocytes at the primary growth stage (S1, Figure 3.1), with a low oocyte diameter $(189.4 \pm 13.4 \mu \mathrm{m})$ at day 1 (Figure 3.2). At day 78, oocytes at the late cortical alveoli stage (S3, 23.8\%) and early vitellogenesis (S4, 14.5\%) were observed in females reared under NSP, whereas only $7.8 \%$ and $1.4 \%$ of oocytes attained early (S2) and late (S3) 
cortical alveoli stage respectively, in those reared under CP (Figure 3.1). At day 149, oocytes reached early vitellogenesis stage $(\mathrm{S} 4,10.5 \%)$ and late vitellogenesis stage $(\mathrm{S} 5,35.2 \%)$ in females reared under NSP while the ovaries of those reared under CP showed atresia (S6, $22 \%$ ), in addition to a majority of oogonia (S1, 68.8\%). The oocyte diameter (Figure 3.2) showed a strong increase in females reared under NSP between day 1 and day $149(\mathrm{p}<0.001)$, and a slight increase in those reared under CP between day 1 and day 78 ( $\mathrm{p}=0.031)$. At day 78 and day 149, the oocyte diameter was significantly higher in females reared under NSP relatively to those reared under $\mathrm{CP}(\mathrm{p}=0.003$ and $\mathrm{p}=0.045$, respectively). Females from the latter treatment also showed a large inter-individual variability in the oocyte diameter at day $149(442.3 \pm 187 \mu \mathrm{m}, \mathrm{CV}=42.2 \%)$

Males reared under NSP showed testis with some spermatocytes (5.8\% and 5\%) at days 78 and 149 respectively, while those reared under CP showed only Type A and B spermatogonia (Figure 3.3).

\subsubsection{Plasma steroids}

- Plasma estradiol

In females, plasma levels of E2 varied significantly depending on photoperiod $(\mathrm{p}<0.001$, Figure 4.1), and sampling time ( $\mathrm{p}<0.001$, Figure 4.2) independently. Plasma levels of E2 were significantly higher in females reared under NSP than in those reared under $\mathrm{CP}(\mathrm{p}=0.002)$ throughout the time. At day 149, these levels were significantly higher than at day 78 regardless of the photoperiod $(\mathrm{p}=0.002)$ but were not significantly different from those observed at day $1(\mathrm{p}=0.105)$.

- Plasma androgens

The plasma testosterone levels varied greatly between individuals (CV>65\%) with no significant effect of photoperiod or sampling time. Plasma levels of $11 \mathrm{KT}$ varied significantly 
depending on the interaction between photoperiod and sampling time in both females $(\mathrm{p}<0.001$, Figure 5.1) and males $(\mathrm{p}<0.001$, Figure 5.2). These levels increased significantly between day 1 and day 149 in females reared under $\mathrm{CP}(\mathrm{p}=0.002)$ while in those reared under NSP, $11 \mathrm{KT}$ levels increased significantly between day 1 and day $78(\mathrm{p}=0.03)$ and remained stable between day 78 and day 149. At day 78 and day 149, 11KT levels were significantly higher in females reared under NSP compared to those reared under $\mathrm{CP}(\mathrm{p}=0.001$ and $\mathrm{p}=0.035$ respectively). In males, 11-KT levels increased significantly between day 1 and day 78 in both group ( $p<0.001$ in NSP group and $p=0.003$ in $\mathrm{CP}$ group) and remained stable between day 78 and day 149 (Figure 5.2). At days 78 and 149, males reared under NSP showed significantly higher $11-\mathrm{KT}$ values than those reared under $\mathrm{CP}(\mathrm{p}<0.001$ for day 78 and $\mathrm{p}=0.017$ for day 149$)$.

\subsubsection{Plasma vitellogenin}

Plasma ALP levels measured in females varied significantly depending on photoperiod, and sampling time (Figure 6). These levels were significantly higher in females reared under NSP compared to those reared under CP $(\mathrm{p}<0.001)$. Additionally, plasma ALP levels increased significantly only between day 78 and day $149(\mathrm{p}<0.001)$. 


\section{Discussion}

\subsection{Effect of photoperiod on females}

295

296

Gonad development, oogenesis development stage, and oocyte diameter, varied throughout the experiment for females depending on the photoperiod. This development showed an important increase of GSI under photoperiod decrease only (3 times higher than at day 1), increase of oocyte diameter (2.5 times higher than at day 1$)$ and advanced oogenesis developmental stages (appareance of early vitellogenesis at day 78). The decrease of photoperiod by more than three hours between day 1 and day 78 allowed the induction of the reproductive cycle in females. Our results are in concordance with the observations made by Geraudie et al. (2010a, b) that found GSI close to $7 \%$ in November in wild populations of roach in the region of Haute Normandie (France), and strengthen the observed similarities in the gonad development rhythms between roach and Eurasian perch caught in the wild (Lukšienè and Svedang 1997). In fact, this response is similar to results obtained in percids like Eurasian perch (Migaud et al., 2006), yellow perch Perca flavescens (Shewmon et al., 2007), and pikeperch Sander lucioperca (Ben Ammar et al., 2015), in which the decreasing photoperiod triggers the onset of the reproductive cycle. Our results also showed a partial inhibition of the induction of the reproductive cycle by a long constant photoperiod. In fact, in females reared under $\mathrm{CP}$, the sudden temperature decrease between day 78 and day 149 induced the reproductive cycle, with a significant increase of GSI and oocyte diameter, and the appearance in the ovaries of oocytes at cortical alveoli stage. Thus, it seems that, even under constant long photoperiod, oocytes maintain a real potential of growth and oogenetic development. Therefore, we have little knowledge of the oogenesis developmental stage from which we can consider that the reproductive cycle is well induced and can lead to the progress of vitellogenesis, final oocyte maturation, and spawning. In the study of Milla et al. (2009), the vitellogenesis stage seems to be the critical stage that cannot be reached if the photoperiod 
and temperature applied to Eurasian perch broodstock are constant. The same phenomenon seems to exist in roach females when only temperature decreases. In fact, under this photoperiod, the most advanced stage reached was alveoli cortical, with high variability in oocyte diameter between individuals $(\mathrm{CV}=42.2)$. Moreover, we observed $25 \%$ of atresia at day 149 only in roach female's ovaries reared under CP, suggesting that constant long photoperiod displays also deleterious effects on oogenesis. All these results allow us to conclude that, even though constant long photoperiod seems to be permissive when associated to a temperature decrease, this photoperiod partly inhibits the reproductive cycle, and may lead to oocyte regression before the spawning period.

The estradiol-controlled production of vitellogenin seems to be a conserved mechanism in teleosts (Atkinson and Yoshioka, 2007). The increase of plasma E2 and ALP levels in females reared under NSP is due to the hepatic vitellogenin synthesis and its incorporation in the oocytes under the regulation of E2 (Babin et al., 2007; Lubzens et al., 2010). This vitellogenin synthesis increases the liver weight, which may explain the more elevated HSI observed in NSP females, as shown in other species like walleye Sander vitreus (Henderson et al., 1996) and pikeperch (Ben Ammar et al., 2015).

Plasmatic levels of 11-ketostestosteone increased at the alveoli cortical stage (day 78) and remained higher in females reared under NSP, compared to those reared under CP. A slight but significant increase was also observed at day 149 in females reared under $\mathrm{CP}$, when ovaries showed oocytes at the alveoli cortical stage. Similar to pikeperch, our results suggest a potential role of this non-aromatizable androgen at the alveoli cortical stage for female roach reared under the natural photoperiod (Ben Ammar et al., 2015). Other studies suggest that 11KT may be involved in the transition to the alveoli cortical stage, and the increase of the oocyte diameter in short-finned eel Anguilla australis (Divers et al., 2010; Lokman et al., 
2007; Rohr et al., 2001). The presence of alveoli cortical oocytes in the females reared under

CP seems to be linked to the slight increase of 11-KT observed at day 149 .

\subsection{Effect of photoperiod on males}

The GSI variation in males reared under NSP showed an increase about 1.9 fold when photoperiod decreased alone (between day 1 and day 78), which was followed by a stronger increase ( 3 fold) when both photoperiod and temperature decreased concomitantly. The increase of GSI is mainly due to the increase of spermatogonia number during successive rounds of mitotic duplication (Schulz and Nóbrega, 2011). Conversely to what we observed in females, spermatic development was interrupted between day 78 and day 149, and male roach testis did not exhibit cells in more advanced stage than spermatocytes in the same proportion. However, roach males reared under CP exhibit only spermatogonia A and B in their testis. It seems that this spermatogenesis process does not display the same advancement, compared to other early spring spawners like Eurasian perch (Sulistyo et al., 2000), pikeperch, (Ben Ammar et al., 2015) and yellow perch (Shewmon et al., 2007). This delay observed in roach males reared under NSP suggests that this species may present other regulatory mechanisms or different sensitivity to the environmental factors. For example, in pike males, another early spring spawner, applying a constant long photoperiod seems to slow spermatogenesis (Ben Ammar et al. 2017). Some authors have reported an interruption of spermatogenesis in the beginning of winter, with resumption in February, in temperate waters (Escaffre and Billard, 1976). The most differentiated stages appear in March (spermatid) and in April (spermatozoa), with males spermiating between May and July (Leman Lake, France, Escaffre and Billard, 1976). These observations made in the wild are close to our results, although caution should be taken when comparing wild fish and RAS reared ones. The interruption of spermatogenic development observed in roach can be explained by the characteristics of the spermatogenic cycle. In other early spring spawners like Eurasian perch (Sulistyo et al., 
2000), pike Esox lucius (Cakić and Lenhardt, 2002), yellow perch (Shewmon et al., 2007) and pikeperch (Ben Ammar et al., 2015), the spermatogenesis and spermiogenesis occurs rapidly and the spermiating males show testis full of spermatozoa about 150 days after the beginning of photoperiod decrease. In roach, it seems that the spermatogenesis phase would last longer, with a shorter spermiogenesis phase, and a rapid elimination of spermatozoa after their formation. The time-course of this spermatogenic cycle may be related to other abiotic factors, like temperature, as the spermatogenetic changes require some temperature threshold (Koskimies-Soininen and Nyberg, 1991; Lofts et al., 1968). In Lake Chub, Coesius plumbeus (cyprinid), high temperatures promote proliferation of spermatogonia and hasten or terminate spermiation, while low temperatures are essential to the formation of the primary spermatocytes (Koskimies-Soininen and Nyberg, 1991). In roach, it may be possible that the return to warm temperature is necessary to hasten the meiotic divisions and engage the spermiogenesis and spermiation in testis as observed in wild (Geraudie et al., 2010a).

In fish, 11-KT is considered as the major androgen regulating spermatogenesis (Mylonas et al., 2010). In the present study, constant long photoperiod negatively affected its synthesis, and 11-KT presented higher levels in males reared under NSP at the end of the experiment. Androgens mediate and regulate the whole process, or at least some steps, of fish spermatogenesis (Billard et al., 1982; Borg, 1994; Fostier et al., 1983). Previous studies in Japanese eel Anguilla japonica, goldfish Carassius auratus, and Japanese huchen Hucho perryi support the involvement of $11-\mathrm{KT}$ in this process from spermatogonial renewal to spermiogenesis (Amer et al., 2001; Miura and Miura, 2011; Miura et al., 1991; Schulz et al., 2010). In Eurasian perch (Sulistyo et al., 2000), walleye (Malison et al., 1994), and yellow perch (Dabrowski, 1996), previous studies found that 11-KT remained at high levels until the spawning season. It seems that, like in those species, 11-KT may be involved in all spermatogenetic changes in roach. 
Constant long photoperiod had an inhibitory effect especially on the most integrative parameters like GSI in both females and males, oocyte diameter and oogenesis process in females. It also affected the most conserved mechanism like synthesis of E2 and the regulation of vitellogenin synthesis under E2 control in females and the regulation of the spermatogenesis by 11-KT in males. In contrast, the photoperiod decrease allowed the induction of the reproductive cycle in both females and males. However, the partial inhibition of GSI observed in females, or the interruption of the spermatic development observed in males can be explained by the potential role of other abiotic factors, like temperature, or the existence of different regulation mechanisms.

\section{Acknowledgments}

We would like to thank all members of the AFPA research unit for their active collaboration in this study. We would also like to thank Julien Ruelle and Maryline Harroué from UMR 1092 AgroParisTech INRA Laboratoy of study of forest and wood ressouces "LERFoB", technical platform xylosciences for the provision of the necessary equipment to realize the histological analyses (Technical Platform of functional ecogenomics, INRA Champenoux, France). We are thankfull to Daniel Van Vlaender (Facultés Universitaires Notre-Dame de la Paix FUNDP, Belgium) for his help with histological protocols, Jos Fey (Faculty of Kinesiology and Rehabilitation Science, University of Leuven), Marie Fernandez (University of Saint Etienne, France) for their advices about statistics with R software, and Mark Holmes (University of Namur, Belgium) for the proofreading.

\section{Funding}

This study was partly funded by the Tunisian Ministry of Higher Education and Research. 


\section{References}

Amer, M. a, Miura, T., Miura, C., Yamauchi, K., 2001. Involvement of sex steroid hormones in the early stages of spermatogenesis in Japanese huchen (Hucho perryi ). Biol. Reprod. 65, 1057-1066. https://doi.org/10.1095/biolreprod65.4.1057

Atkinson, S., Yoshioka, M., 2007. Endocrinology of Reproduction, in: Reproductive Biology and Phylogeny of Cetacea: Whales, Porpoises and Dolphins2. Science Publishers, pp. 171-192. https://doi.org/doi:10.1201/b10257-3

Babin, P.J., Carnevali, O., Lubzens, E., Schnider, W.J., 2007. Molecular aspects of oocyte vitallogenesis in fish, in: Babin, P.J., Cerdà, J., Lubzens, E. (Eds.), The Fish Oocyte: From Basic Studies to Biotechnological Applications. Springer, The Netherlands, pp. $39-78$.

Baggerman, B., 1980. Photoperiod and endogenous control of the annual reproductive cycle in teleost fishes, in: Ali, M.A. (Ed.), Environmental Physiology of Fishes. Springer US, Boston, MA, pp. 533-567. https://doi.org/10.1007/978-1-4899-3659-2_21

Bates, D., Mächler, M., Bolker, B., Walker, S., 2014. Fitting linear mixed-effects models using lme4. J. Stat. Softw. 67. https://doi.org/10.18637/jss.v067.i01

Bayarri, M.J., Rodríguez, L., Zanuy, S., Madrid, J.A., Sánchez-Vázquez, F.J., Carrillo, M., 2004. Effect of photoperiod manipulation on daily rhythms of melatonin and reproductive hormones in caged European sea bass (Dicentrarchus labrax). Gen. Comp. Endocrinol. 136, 72-81. https://doi.org/10.1023/B:FISH.0000030468.98771.c0

Ben Ammar, I., Milla, S., Missaoui, H., Ledoré, Y., Teletchea, F., Fontaine, P., 2017. Does constant photoperiod inhibit the onset of the reproductive cycle in northern pike (Esox lucius) males? Fish Physiol. Biochem. 1-10. https://doi.org/10.1007/s10695-017-0435-3

Ben Ammar, I., Teletchea, F., Milla, S., Ndiaye, W.N., Ledoré, Y., Missaoui, H., Fontaine, P., 2015. Continuous lighting inhibits the onset of reproductive cycle in pikeperch males and females. Fish Physiol. Biochem. 41, 345-356. https://doi.org/10.1007/s10695-014-99877

Billard, R., Fostier, A., Weil, C., Breton, B., 1982. Endocrine Control of Spermatogenesis in Teleost Fish. Can. J. Fish. Aquat. Sci. 39, 65-79. https://doi.org/10.1139/f82-009

Borg, B., 1994. Androgens in teleost fishes. Comp. Biochem. Physiol. Part C Comp. 109, 219-245. https://doi.org/10.1016/0742-8413(94)00063-G

Borg, B., Ekström, P., 1981. Gonadal effects of melatonin in the three-spined stickleback, Gasterosteus aculeatus L., during different seasons and photoperiods. Reprod. Nutr. Dev. 21, 919-927.

Bornestaf, C., Antonopoulou, E., Mayer, I., Borg, B., 1997. Effects of aromatase inhibitors on reproduction in male three-spined sticklebacks, Gasterosteus aculeatus, exposed to long and short photoperiods. Fish Physiol. Biochem. 16, 419-423.

Bromage, N., Porter, M., Randall, C., 2001. The environmental regulation of maturation in fermed finfish with special reference to the role of photoperiod and melatonin. Aquaculture 197, 63-68. 
Cakić, M., Lenhardt, P., 2002. Seasonal reproductive cycle of pike, Esox lucius L., from the River Danube. J. Appl. Ichthyol. 18, 7-13. https://doi.org/10.1046/j.14390426.2002.00285.x

Dabrowski, K., 1996. Reproductive physiology of yellow perch (Perca flavescens): environmental and endocrinological cues. J. Appl. ... 12, 139-148. https://doi.org/10.1111/j.1439-0426.1996.tb00079.x

Davies, P.R., Hanyu, I., 1986. Effect of Temperature and Photoperiod on Sexual Maturation and Spawning of the Common Carp I. Under Conditions of High Temperature*. Aquac. Elsevier Sci. Publ. B.V 51, 277-288.

Davies, P.R., Hanyu, I., Furukawa, K., Nomura ', M., 1986. Effect of Temperature and Photoperiod on Sexual Maturation and Spawning of the Common Carp Ii. Under Conditions of Low Temperature*. Aquac. Elsevier Sci. Publ. B.V 52, 51-58. https://doi.org/10.1016/0044-8486(86)90107-9

Dey, R., Bhattacharya, S., Maitra, S.K., 2005. Importance of photoperiods in the regulation of ovarian activities in Indian major carp Catla catla in an annual cycle. J. Biol. Rhythms 20, 145-158. https://doi.org/10.1177/0748730404272925

Divers, S.L., McQuillan, H.J., Matsubara, H., Todo, T., Lokman, P.M., 2010. Effects of reproductive stage and 11-ketotestosterone on LPL mRNA levels in the ovary of the shortfinned eel. J. Lipid Res. 51, 3250-3258. https://doi.org/10.1194/jlr.M009027

Escaffre, A., Billard, R., 1976. Le cycle spermatogénétique du Gardon Rutilus rutilus. Cah. du Lab. Montereau 3, 43-46.

Fostier, A., Jalabert, B., Billard, R., Breton, B., Zohar, Y., 1983. The gonadal steroids, in: Hoar, S.W., Randall, D.J., Donaldson, E.M. (Eds.), Fish Physiology. pp. 277-372. https://doi.org/10.1016/S1546-5098(08)60291-5

Fox, J., Weisberg, S., Adler, D., Bates, D., Baud-, G., Ellison, S., Firth, D., Friendly, M., Gor, G., Graves, S., Heiberger, R., Laboissiere, R., Mon-, G., Murdoch, D., Nilsson, H., Ogle, D., Rip-, B., 2014. Package 'car' (Version 2.1-3), Second. ed, URL https://rforge.r-project.org/projects/car/, http://CRAN.R-project.org/package=car, http://socserv.socsci.mcmaster.ca/jfox/Books/Companion/index.html. SAGE Publications, Inc.

Gagné, F., Blaise, C., 2000. Organic alkali-labile phosphates in biological materials: A generic assay to detect Vitellogenin in biological tissues. Environ. Toxicol. 15, 243-247. https://doi.org/10.1002/1522-7278(2000)15:3<243::AID-TOX9>3.0.CO;2-D

Geraudie, P., Gerbron, M., Hill, E., Minier, C., 2010a. Roach (Rutilus rutilus) reproductive cycle: A study of biochemical and histological parameters in a low contaminated site. Fish Physiol. Biochem. 36, 767-777. https://doi.org/10.1007/s10695-009-9351-5

Geraudie, P., Gerbron, M., Minier, C., 2010b. Seasonal variations and alterations of sex steroid levels during the reproductive cycle of male roach (Rutilus rutilus). Mar. Environ. Res. 69, S53-S55. https://doi.org/10.1016/j.marenvres.2009.11.008

Gillet, C., Quétin, P., 2006. Effect of temperature changes on the reproductive cycle of roach in Lake Geneva from 1983 to 2001. J. Fish Biol. 69, 518-534. https://doi.org/10.1111/j.1095-8649.2006.01123.x 
Henderson, B. a, Wong, J.L., Nepszy, S.J., 1996. Reproduction of walleye in Lake Erie: allocation of energy. Can. J. Fish. Aquat. Sci. 53, 127-133. https://doi.org/10.1139/f95162

Hervé, M., 2015. R package 'RVAideMemoire': Diverse Basic Statistical and Graphical Functions. Version: 0.9-45-2.

Higgins, J.J., Tashtoush, S., 1994. An aligned rank transform test for interaction. Nonlinear World 1, 201-211.

Imsland, A.K., Folkvord, A., Jónsdóttir, Ó.D.B., Stefansson, S.O., 1997. Effects of exposure to extended photoperiods during the first winter on long-term growth and age at first maturity in turbot (Scophthalmus maximus). Aquaculture 159, 125-141. https://doi.org/10.1016/S0044-8486(97)00152-X

Kestemont, P., 1990. Dynamic aspects of ovogenesis in an asynchronous fish, the gudgeon Gobio gobio L.(Teleostei, Cyprinidae), under controlled temperature and photoperiod conditions. Aquat. living Resour. 3, 61-74.

Knapp, R., Carlisle, S.L., 2011. Testicular function and hormonal regulation in fishes, in: Hormones and Reproduction of Vertebrates. Elsevier, pp. 43-63.

Koskimies-Soininen, K., Nyberg, H., 1991. Effects of temperature and light on the glycolipids of Sphagnum fimbriatum. Phytochemistry 30, 2529-2536. https://doi.org/10.1016/00319422(91)85094-G

Langeron, M., 1913. Précis de microscopie: technique, expérimentation, diagnostic. Libraires de l'académie de médecine, Paris.

Le Menn, F., Cerdà, J., Babin, P.J., 2007. Ultrastructural aspects of the ontogeny and differentiation of ray-finned fish ovarian follicles, in: The Fish Oocyte. Springer, pp. 137.

Lenth, R. V., 2016. Least-Squares Means: The R Package lsmeans. J. Stat. Softw. 69, 1-33. https://doi.org/10.18637/jss.v069.i01

Lofts, B., Pickford, G.E., Atz, J.W., 1968. The effects of low temperature, and cortisol, on testicular regression in the hypophysectomized cyprinodont fish, Fundulus heteroclitus. Biol. Bull. 134, 74-86.

Lokman, P.M., George, K.A.N., Divers, S.L., Algie, M., Young, G., 2007. 11Ketotestosterone and IGF-I increse the size of previttelogenic oocytes from shortfinned eel, Anguilla australis, in vitro. Reproduction 133, 955-967. https://doi.org/10.1530/REP-06-0229

Lubzens, E., Young, G., Bobe, J., Cerdà, J., 2010. Oogenesis in teleosts: How fish eggs are formed. Gen. Comp. Endocrinol. 165, 367-389. https://doi.org/10.1016/j.ygcen.2009.05.022

Lukšienè, D., Svedang, H., 1997. A rewiew on fish reproduction with special reference to temperature anomalies. Fisk. Kustlaboratoriet 35 p.

Malison, J.A., Procarione, L.S., Barry, T.P., Kapuscinski, A.R., Kayes, T.B., 1994. Endocrine and gonadal changes during the annual reproductive cycle of the freshwater teleost, 
Stizostedion vitreum. Fish Physiol. Biochem. 13, 473-484. https://doi.org/10.1007/BF00004330

Migaud, H., Davie, A., Taylor, J.F., 2010. Current knowledge on the photoneuroendocrine regulation of reproduction in temperate fish species. J. Fish Biol. 76, $27-68$. https://doi.org/10.1111/j.1095-8649.2009.02500.x

Migaud, H., Fontaine, P., Kestemont, P., Wang, N., Brun-Bellut, J., 2004a. Influence of photoperiod on the onset of gonadogenesis in Eurasian perch Perca fluviatilis. Aquaculture 241, 561-574. https://doi.org/10.1016/j.aquaculture.2004.07.031

Migaud, H., Gardeur, J.N., Kestemont, P., Fontaine, P., 2004b. Off-season spawning of Eurasian perch Perca fluviatilis. Aquac. Int. 12, 87-102. https://doi.org/10.1023/B:AQUI.0000017190.15074.6c

Migaud, H., Wang, N., Gardeur, J.N., Fontaine, P., 2006. Influence of photoperiod on reproductive performances in Eurasian perch Perca fluviatilis. Aquaculture 252, 385393. https://doi.org/10.1016/j.aquaculture.2005.07.029

Milla, S., Mandiki, S.N.M., Hubermont, P., Rougeot, C., Mélard, C., Kestemont, P., 2009. Ovarian steroidogenesis inhibition by constant photothermal conditions is caused by a lack of gonadotropin stimulation in Eurasian perch. Gen. Comp. Endocrinol. 163, 242250. https://doi.org/10.1016/j.ygcen.2009.04.010

Miura, C., Higashino, T., Miura, T., 2007. A progestin and an estrogen regulate early stages of oogenesis in fish. Biol. Reprod. 77, 822-828.

Miura, C., Miura, T., 2011. Analysis of Spermatogenesis Using an Eel Model. AquaBioScience Monogr. 4, 105-129. https://doi.org/10.5047/absm.2011.00404.0105

Miura, T., Yamauchi, K., Takahashi, H., Nagahama, Y., 1991. Hormonal induction of all stages of spermatogenesis in vitro in the male Japanese eel (Anguilla japonica). Proc. Natl. Acad. Sci. U. S. A. 88, 5774-5778. https://doi.org/10.1073/pnas.88.13.5774

Mylonas, C.C., Fostier, A., Zanuy, S., 2010. Broodstock management and hormonal manipulations of fish reproduction. Gen. Comp. Endocrinol. 165, 516-534. https://doi.org/10.1016/j.ygcen.2009.03.007

Pohlert, T., 2016. Calculate Pairwise Multiple Comparisons of Mean Rank Sums Version 31.

Poncin, P., Melard, C., Philippart, J.C., 1987. Use of Temperature and Photoperiod in the Control of the Reproduction of Three European Cyprinids, Barbus Barbus (L), Leuciscus Cephalus (L.) and Tinca Tinca (L), Reared in Captivity. Preliminary Results. Bull. Français la Pêche la Piscic. 304, 1-12.

R Development Core Team, 2005. R: A language and environment for statistical computing. R Foundation for Statistical Computing, R Foundation for Statistical Computing, Vienna, Austria.

Rinchard, J., Kestemont, P., 1996. Comparative study of reproductive biology in single- and multiple-spawner cyprinid fish. I. Morphological and histological features . J. Fish Biol. 49, 883-894. https://doi.org/DOI 10.1006/jfbi.1996.0219

Rohr, D.H., Lokman, P.M., Davie, P.S., Young, G., 2001. 11-Ketotestosterone induces 
silvering-related changes in immature female short-finned eels, Anguilla australis. Comp. Biochem. Physiol. - A Mol. Integr. Physiol. 130, 701-714. https://doi.org/10.1016/S1095-6433(01)00402-0

Rosa, H.J.D., Bryant, M.J., 2003. Seasonality of reproduction in sheep. Small Rumin. Res. 48, 155-171. https://doi.org/10.1016/S0921-4488(03)00038-5

Schulz, R.W., de França, L.R., Lareyre, J.J., LeGac, F., Chiarini-Garcia, H., Nobrega, R.H., Miura, T., 2010. Spermatogenesis in fish. Gen. Comp. Endocrinol. 165, 390-411. https://doi.org/10.1016/j.ygcen.2009.02.013

Schulz, R.W., Nóbrega, R.H., 2011. Anatomy and Histology of fish testis, in: Farrell, A.P., Cech, J.J., Richards, J.G., Stevens, E.D. (Eds.), Encyclopedia of Fish Physiology: From Genome to Environment. Academic Press / Elsevier, London, pp. 616-626. https://doi.org/10.1016/B978-0-1237-4553-8.00246-X

Scott, D.B.C., 1979. Environmental timing and the control of reproduction in teleost fish, in: Symposium of the Zoological Society of London. pp. 105-132.

Shewmon, L.N., Godwin, J.R., Murashige, R.S., Daniels, H. V., Losordo, T.M., 2007. Environmental manipulation of growth and sexual maturation in yellow perch, Perca flavescens. J. World Aquac. Soc. 38, 383-394.

Stanton, G., 1968. Colorimetric Determination of Inorganic Phosphate in the Presence of Biological Material and Adenosine Triphosphate. Anal. Biochem. 22, $27-34$.

Sulistyo, I., Fontaine, P., Rinchard, J., Gardeur, J.N., Migaud, H., Capdeville, B., Kestemont, P., 2000. Reproductive cycle and plasma levels of steroids in male Eurasian perch Perca fluviatilis. Aquat. Living Resour. 13, 99-106. https://doi.org/10.1016/S09907440(00)00146-7

Sumpter, J.P., 1990. Chp. 2. General Concepts of seasonal reproduction. Reprod. Seas. Teleosts Environ. Influ. 13-31.

Tarkan, A.S., 2006. Reproductive ecology of two cyprinid fishes in an oligotrophic lake near the southern limits of their distributions range. Ecol. Freshw. Fish 15, 131-138. https://doi.org/10.1111/j.1600-0633.2006.00133.x

Teletchea, F., Fontaine, P., 2014. Levels of domestication in fish: Implications for the sustainable future of aquaculture. Fish Fish. 15, 181-195. https://doi.org/10.1111/faf.12006

Teletchea, F., Fostier, A., Kamler, E., Gardeur, J.N., Le Bail, P.Y., Jalabert, B., Fontaine, P., 2009. Comparative analysis of reproductive traits in 65 freshwater fish species: Application to the domestication of new fish species. Rev. Fish Biol. Fish. 19, 403-430. https://doi.org/10.1007/s11160-008-9102-1

Turner, C.L., 1919. The seasonal cycle in the spermary of the perch. J. Morphol. 32, 681-711. https://doi.org/10.1002/jmor.1050320307

Tyler, C.R., Jobling, S., 2008. Roach, sex, and gender-bending chemicals: The feminization of wild fish in English rivers. Bioscience 58, 1051-1059.

Villacorta, P.J., 2015. ART: Aligned Rank Transform for Nonparametric Foctorial Analysis, 
Wang, N., Teletchea, F., Kestemont, P., Milla, S., Fontaine, P., 2010. Photothermal control of the reproductive cycle in temperate fishes. Rev. Aquac. 2, 209-222. https://doi.org/10.1111/j.1753-5131.2010.01037.x

620

Zhu, D., Yang, K., Gul, Y., Song, W., Zhang, X., Wang, W., 2014. Effect of photoperiod on growth and gonadal development of juvenile Topmouth Gudgeon Pseudorasbora parva. Environ. Biol. Fishes 97, 147-156. https://doi.org/10.1007/s10641-013-0133-7

623

624 


\section{Legends}

Fig. 1 Graphical representations of the applied natural photoperiod (NSP, grey continuous line), constant photoperiod (CP, grey discontinuous line) and temperature $\left({ }^{\circ} \mathrm{C}\right.$, black continuous line) values during the whole time-course of the experiment. Sampling times (arrows) are also indicated.

Fig. 2 Effect of photoperiod treatment (NSP: Natural simulated photoperiod, CP: Constant photoperiod) in day 1 , day 78 and day 149 on gonado-somatic index (\%) in females (1) and males (2) of roach Rutilus rutilus. The horizontal line in the box represents the median; the bottom and the top of the box are the first and third quartiles. Whiskers show values within 1.5 times of the interquartile range from the boxes and outliers are plotted as little white circle. Different capital letters (A, B) indicate significant differences between the photoperiod treatment and, lower case letters $(\mathrm{a}, \mathrm{b}, \mathrm{c})$ indicate significant differences among the sampling times ( $\mathrm{p}<0.05)$. Females: $\mathrm{N}=8,11$ and 11 for natural simulated photoperiod NSP and 8, 9 and 12 for constant photoperiod CP at day 1,78 and 149 respectively. Males: N=8, 11 and 11 for NSP and 8, 9 and 12 for CP at day 1,78 and 149 respectively.

Fig. 3 Effect of photoperiod treatment (NSP: Natural simulated photoperiod, CP: Constant photoperiod) on oogenesis development stages observed in ovaries (1) on oocyte diameter $(\mu \mathrm{m})$ and spermatogenesis development stages (3) of roach Rutilus rutilus females and males. (1) S1: Primary growth, S2: early cortical alveoli stage, S3: late cortical alveoli stage, S4: early vitellogenesis, S5: vitellogenesis and S6: atresia. (2) SPGA: spermatgonia A, SPGB: spermatogonia B, SPC: spermatocyte, SPD: spermatid and SPZ: spermatozoa. (3) The horizontal line in the box represents the median; the bottom and the top of the box are the first and third quartiles. Whiskers show values within 1.5 times of the interquartile range from the boxes and outliers are plotted as little white circle. Different capital letters (A, B) indicate significant differences between the photoperiod treatment and, lower case letters $(a, b, c)$ indicate significant differences among the sampling times $(p<0.05) . N=3$ per tank for both sexes in all modalities of photoperiod and sampling time.

Fig. 4 Effect of photoperiod treatment (1, NSP: Natural simulated photoperiod, CP: Constant photoperiod) and sampling time (2) on plasma estradiol levels E2 ( $\mathrm{ng} / \mathrm{mL})$ in females of roach Rutilus rutilus. The horizontal line in the box represents the median; the bottom and the top of the box are the 
652 first and third quartiles. Whiskers show values within 1.5 times of the interquartile range from the

653 boxes and outliers are plotted as little white circle. Different capital letters (A, B) indicate significant

654 differences between the photoperiod treatment and, lower case letters (a, b, c) indicate significant

655 differences among the sampling times ( $\mathrm{p}<0.05)$.(1): $\mathrm{N}=30$ for NSP treatment and 29 for CP treatment.

656 (2): $\mathrm{N}=16,20$ and 23 at day 1,78 and 149 respectively.

657 Fig. 5 Effect of photoperiod treatment (NSP: Natural simulated photoperiod, CP: Constant

658 photoperiod) on plasma 11-ketotestosterone levels 11-KT (ng/mL) in females (1) and males (2) of

659 roach Rutilus rutilus. The horizontal line in the box represents the median; the bottom and the top of

660 the box are the first and third quartiles. Whiskers show values within 1.5 times of the interquartile

661 range from the boxes and outliers are plotted as little white circle. Different capital letters (A, B)

662 indicate significant differences between the photoperiod treatment and, lower case letters (a, b, c)

663 indicate significant differences among the sampling times $(\mathrm{p}<0.05)$. Females: $\mathrm{N}=8,11$ and 11 for

664 natural simulated photoperiod NSP and 8,9 and 12 for constant photoperiod CP at day 1, 78 and 149

665 respectively. Males: N=8, 11 and 11 for NSP and 8, 9 and 12 for CP at day 1, 78 and 149 respectively.

666 Fig. 6 Effect of photoperiod treatment (1, NSP: Natural simulated photoperiod, CP: Constant

667 photoperiod) and sampling time (2) on plasma Alkaline Labile Phosphate levels ALP $(\mu \mathrm{g} / \mathrm{mL})$ in

668 females of roach Rutilus rutilus. The horizontal line in the box represents the median; the bottom and

669 the top of the box are the first and third quartiles. Whiskers show values within 1.5 times of the

670 interquartile range from the boxes and outliers are plotted as little white circle. Different capital letters

671 (A, B) indicate significant differences between the photoperiod treatment and, lower case letters (a, b,

672 c) indicate significant differences among the sampling times ( $<<0.05)$. (1): N=30 for NSP treatment

673 and 29 for $\mathrm{CP}$ treatment. (2): $\mathrm{N}=16,20$ and 23 at day 1,78 and 149 respectively.

674 


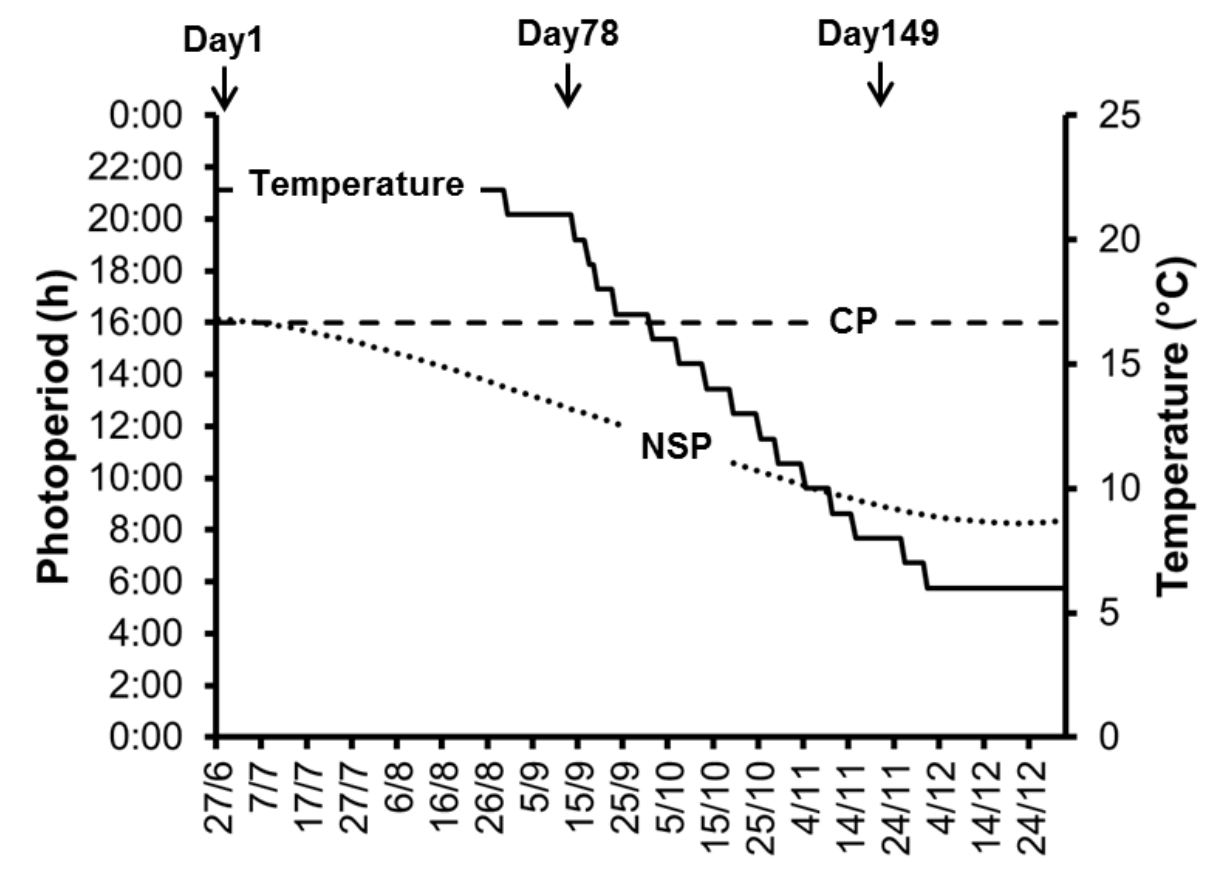

675

\section{Date}

676 Figure 1 Ben Ammar et al.

677 

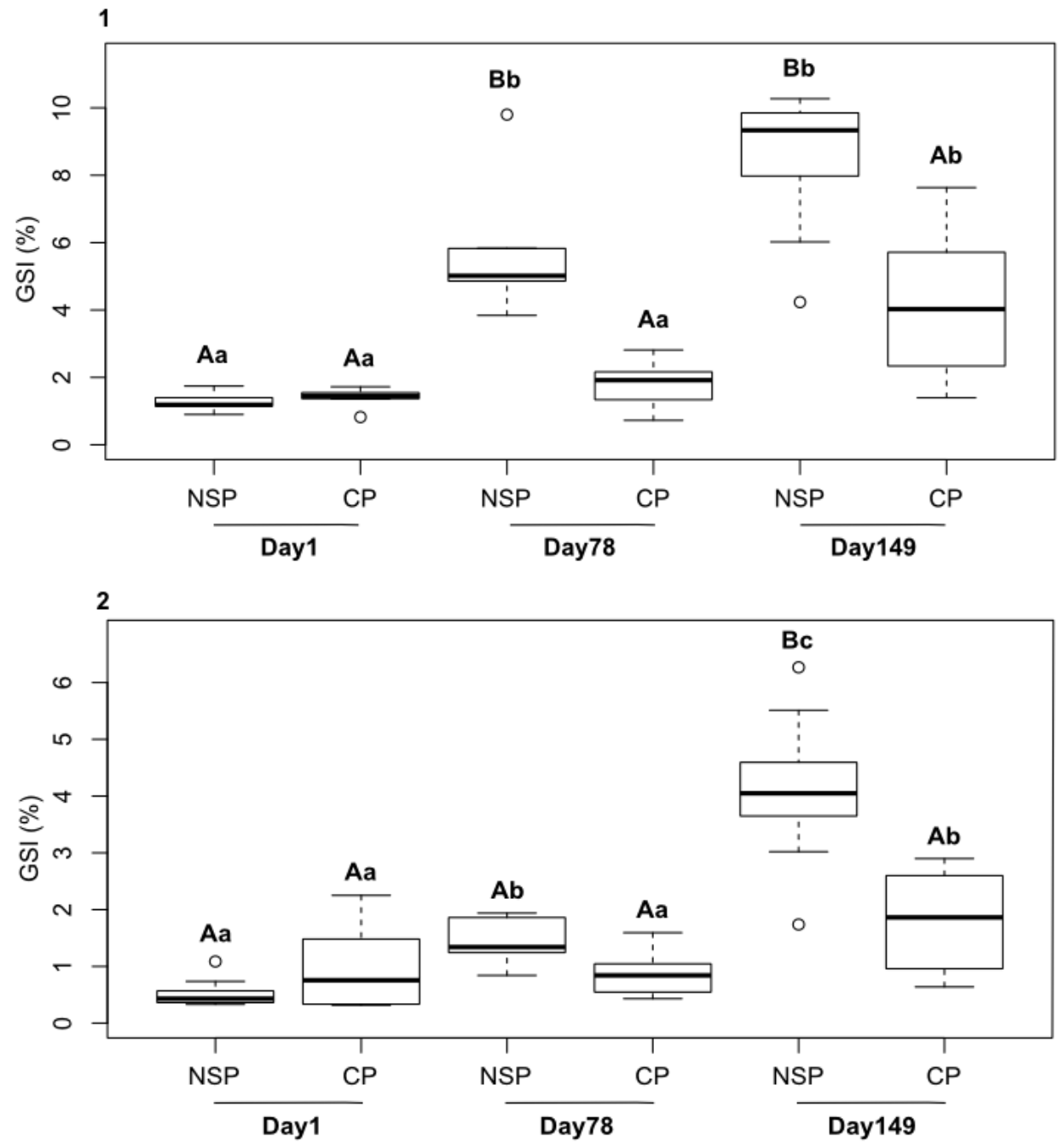

678

679 Figure 2. Ben Ammar et al.

680 


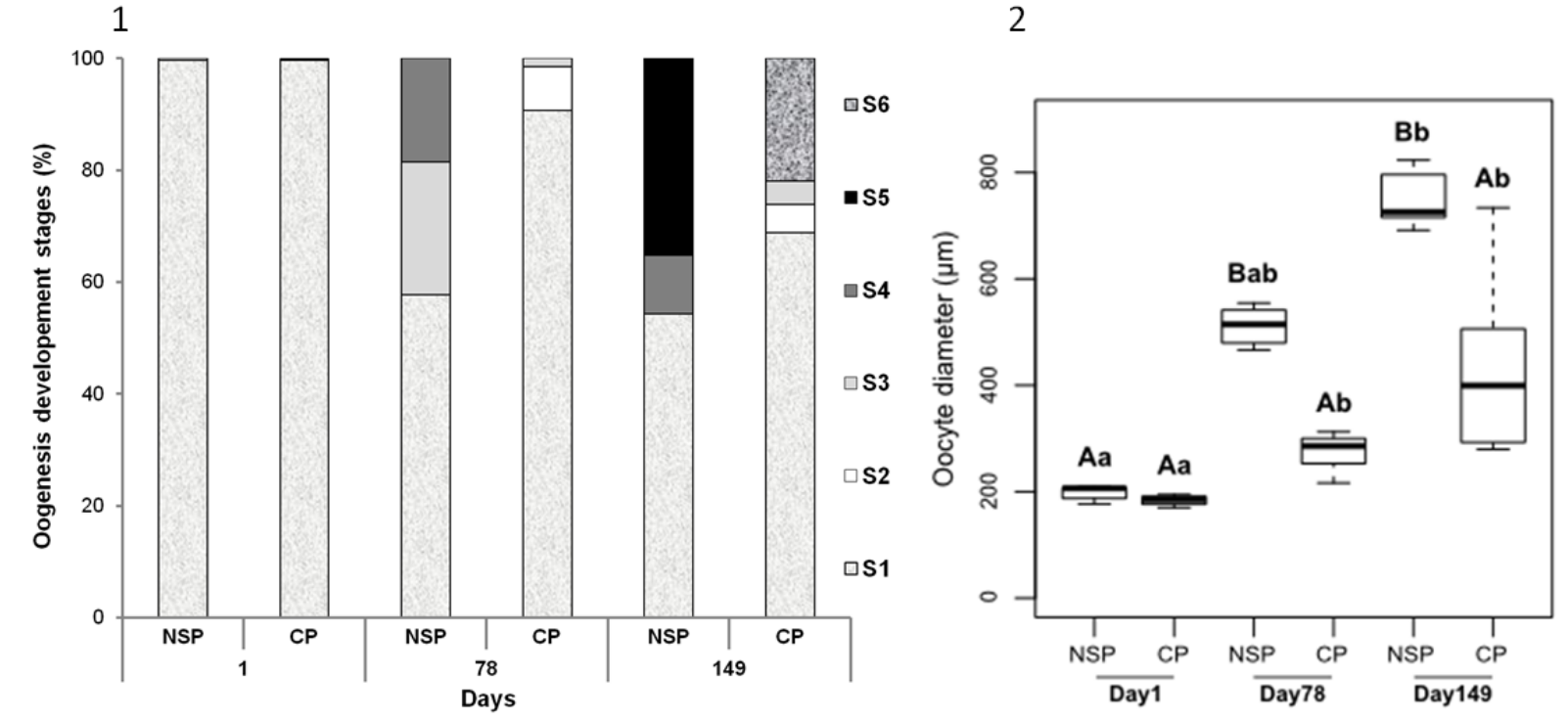

2

681

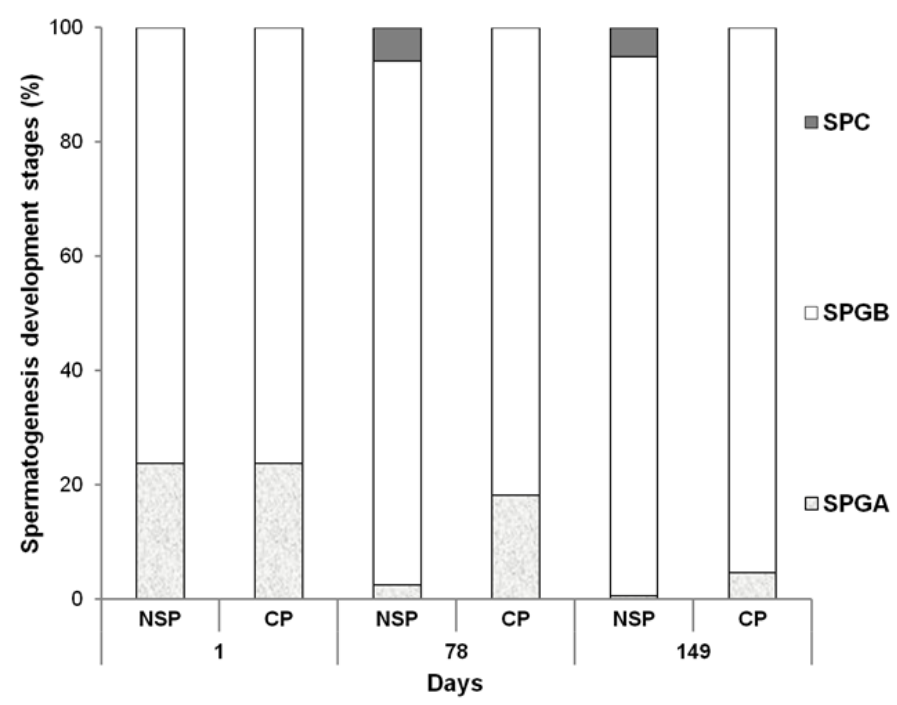

682 Figure 3 Ben Ammar et al

683 

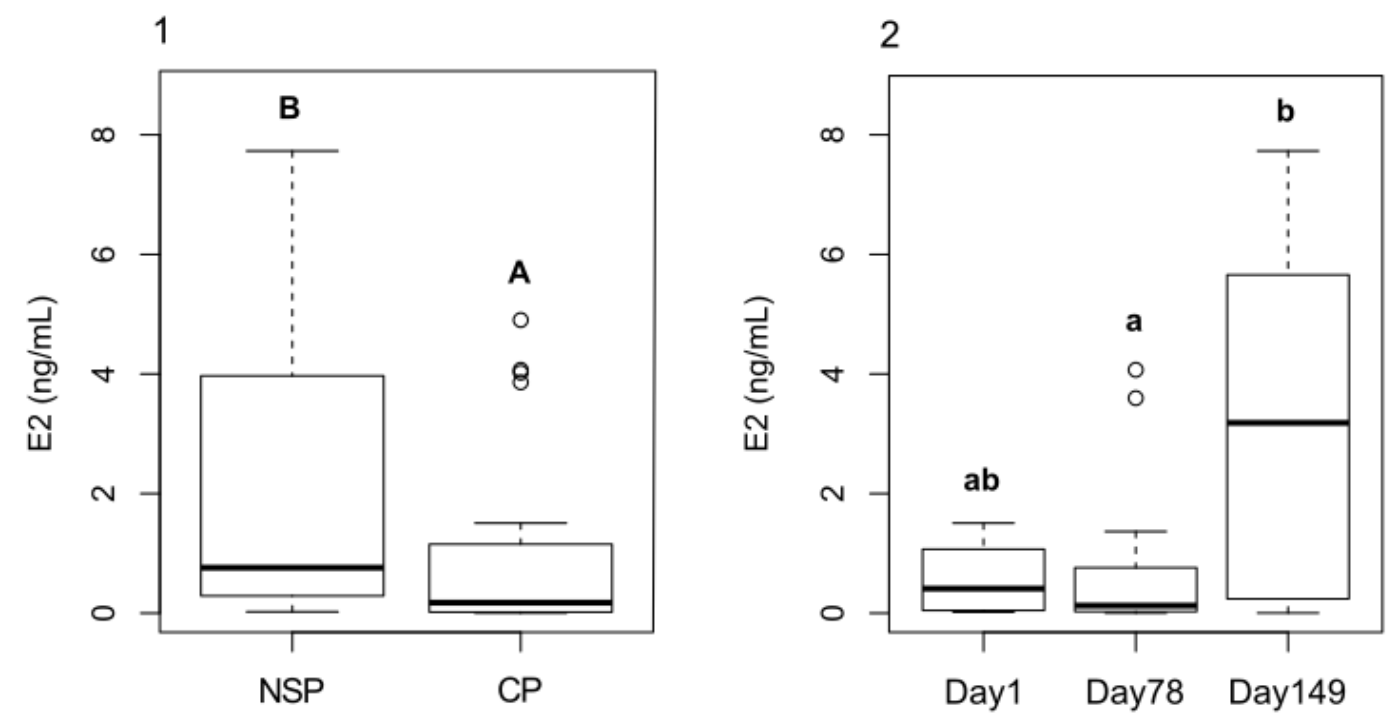

685 Figure 4 Ben Ammar et al

686 

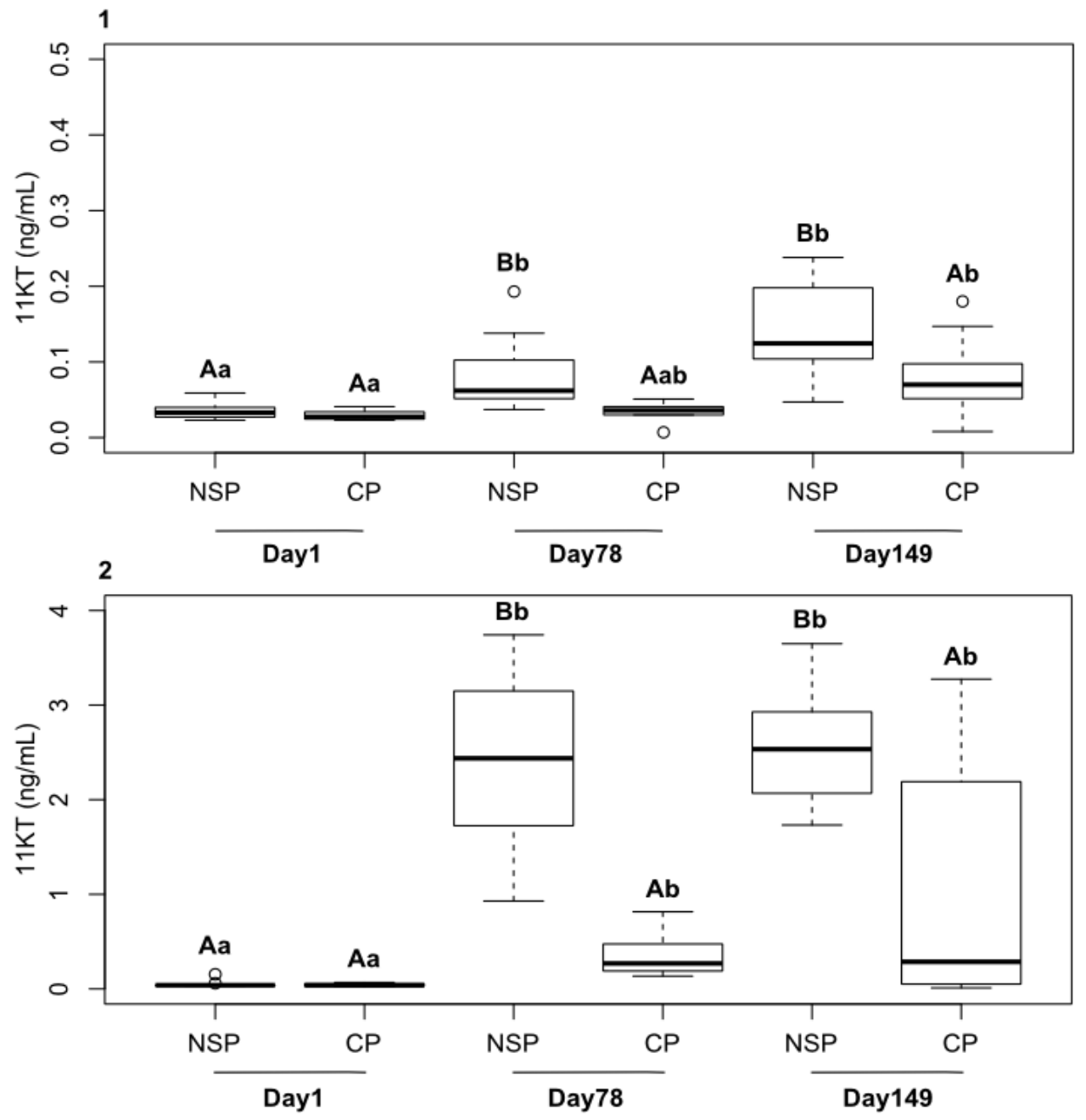

687

688 Figure 5. Ben Ammar et al. 

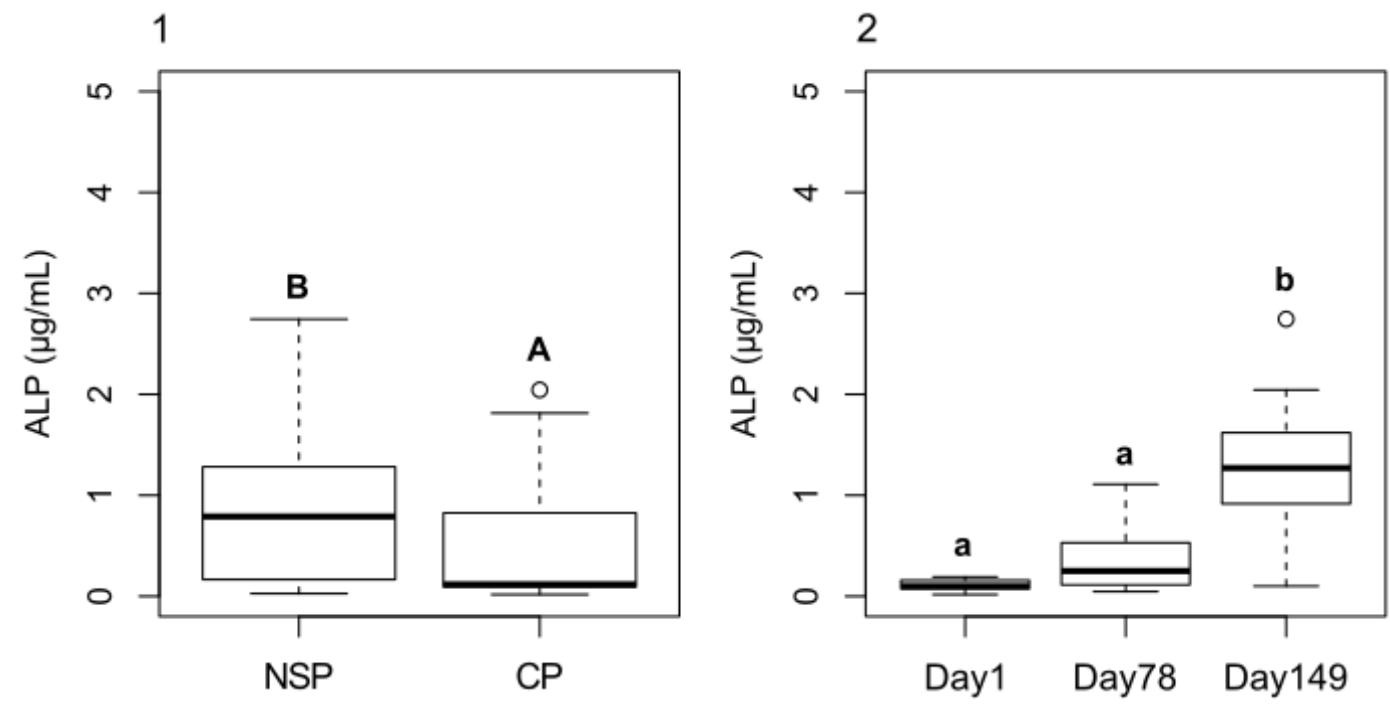

690 Figure 6. Ben Ammar et al. 
691

692

693

694

695

696

697

698

Table 1: Effect of the photoperiod treatment on hepato-somatic index (HSI) and viscero-somatic index (VSI) in females and males of roach Rutilus rutilus (mean \pm SEM). Different capital letters (A, B) indicate significant differences between the photoperiod treatment and, lower case letters $(a, b, c)$ indicate significant differences among the sampling times $(\mathrm{p}<0.05)$. Females: $\mathrm{N}=8,11$ and 11 for natural simulated photoperiod NSP and 8, 9 and 12 for constant photoperiod CP at day 1, 78 and 149 respectively. Males: $\mathrm{N}=8,11$ and 11 for NSP and 8, 9 and 12 for $\mathrm{CP}$ at day 1, 78 and 149 respectively.

\begin{tabular}{|c|c|c|c|c|c|c|c|}
\hline & \multicolumn{3}{|c|}{ Females } & \multicolumn{3}{|c|}{ Males } \\
\hline & & \multicolumn{3}{|c|}{ Time (days) } & \multicolumn{3}{|c|}{ Time (days) } \\
\hline & & 1 & 78 & 149 & 1 & 78 & 149 \\
\hline \multirow{2}{*}{ HSI } & NSP & $1.10 \pm 0.04^{\mathrm{a}}$ & $1.01 \pm 0.06^{\mathrm{a}}$ & $1.71 \pm 0.11^{b}$ & $1.14 \pm 0.06^{\mathrm{a}}$ & $0.95 \pm 0.07^{a}$ & $1.59 \pm 0.19^{b}$ \\
\hline & $\mathrm{CP}$ & $1.10 \pm 0.04^{\mathrm{a}}$ & $0.99 \pm 0.09^{a}$ & $1.97 \pm 0.12^{b}$ & $1.14 \pm 0.06^{\mathrm{a}}$ & $1.05 \pm 0.08^{\mathrm{a}}$ & $2.00 \pm 0.19^{b}$ \\
\hline \multirow{2}{*}{ VSI } & NSP & $5.31 \pm 0.21^{\mathrm{Aa}}$ & $5.77 \pm 0.18^{\mathrm{Aa}}$ & $5.54 \pm 0.27^{\mathrm{Aa}}$ & $5.52 \pm 0.27^{\mathrm{Aa}}$ & $6.67 \pm 0.41^{\mathrm{Aa}}$ & $6.68 \pm 0.24^{A_{C}}$ \\
\hline & $\mathrm{CP}$ & $5.31 \pm 0.21^{\mathrm{Aa}}$ & $6.12 \pm 0.29^{\mathrm{Aa}}$ & $8.38 \pm 0.34^{\mathrm{Bb}}$ & $5.52 \pm 0.27^{\mathrm{Aa}}$ & $6.05 \pm 0.67^{\mathrm{Aa}}$ & $8.86 \pm 0.50^{\mathrm{Bb}}$ \\
\hline
\end{tabular}

699 